\title{
Severe suicidal digoxin toxicity managed with resin hemoperfusion: A case report
}

\author{
Deven Juneja, Omender Singh, Alka Bhasin, Manish Gupta, Sanjay Saxena, Archana Chaturvedi
}

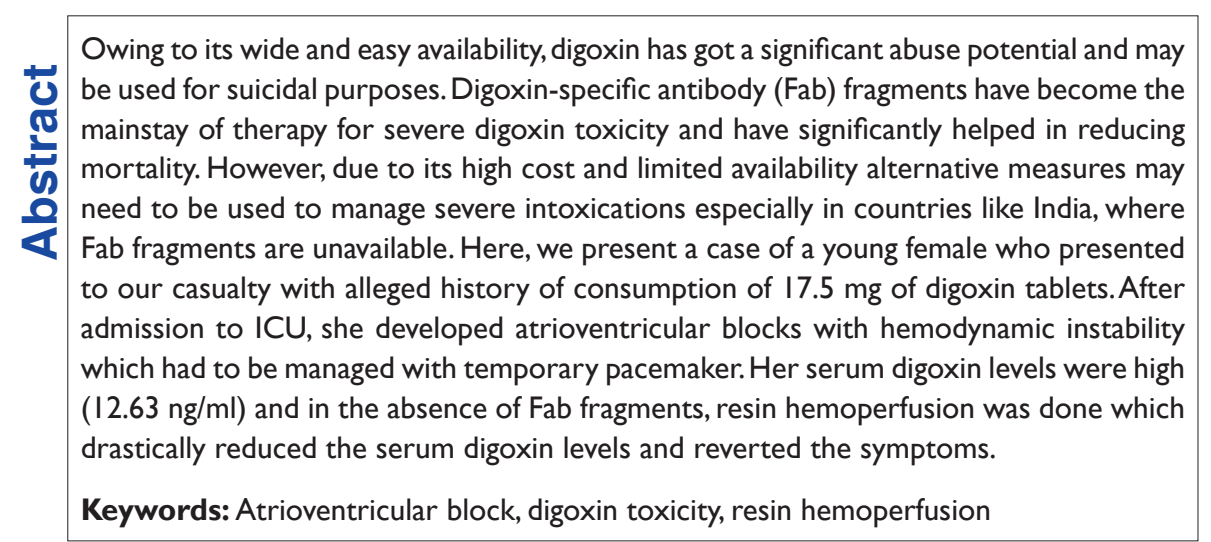

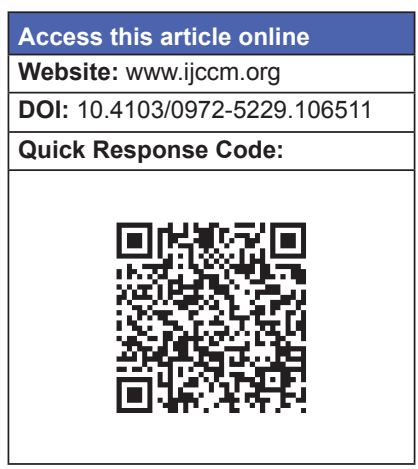

\section{Introduction}

Digoxin is widely used in the management of cardiovascular disorders. Because of its narrow therapeutic index, there is a high probability of accidental overdose leading to toxicity. Moreover, as it is widely and easily available, it has got a significant abuse potential and may be used for suicidal purposes. ${ }^{[1]}$

Recently, digoxin-specific antibody (Fab) fragments have been shown to be effective in safely and quickly eliminating digoxin from blood and reduce mortality and hence, have become the mainstay of therapy in patients with digoxin toxicity. ${ }^{[2,3]}$ However, it is not widely available, especially in countries like India, where only conservative symptomatic therapy may be offered to patients with digoxin toxicity. Due to high mortality associated with severe digoxin toxicity it becomes imperative that other alternative approaches may be

From:

Departments of Critical Care Medicine, and Nephrology, Max Super Speciality Hospital, New Delhi, India

\section{Correspondence:}

Dr. Deven Juneja, Institute of Critical Care Medicine, Max Super Speciality Hospital, 1, Press Enclave Road, Saket, New Delhi, India.

E-mail: devenjuneja@gmail.com tried to improve outcome. However, there is dearth of data regarding successful use of such therapies. Here we present a case of suicidal ingestion of large quantities of digoxin which was effectively managed by using resin hemofilteration in the absence of Fab fragments.

\section{Case Report}

A 30 year old female presented to casualty with an alleged history of ingestion of 70 tablets of $0.25 \mathrm{mg}$ digoxin (total dose $17.5 \mathrm{mg}$ ) one hour prior to presentation. She had developed nausea and recurrent vomiting 20 minutes after ingestion. Immediate gastric lavage was done and activated charcoal $100 \mathrm{gm}$ was given through nasogastric tube. One gram magnesium sulphate was also given intravenously. On examination, she was conscious, oriented, afebrile, and had a heart rate of 102/minute, $\mathrm{BP}$ of $106 / 70 \mathrm{mmHg}$, respiratory rate of $20 /$ minute, and was maintaining oxygen saturation of $99 \%$ on room air. Systemic examination was unremarkable and her initial electrocardiograph showed normal sinus rhythm. All routine laboratory tests were sent along with serum digoxin levels and urine toxicology screen. She was immediately shifted to ICU.

Initial investigations revealed serum digoxin levels of $12.63 \mathrm{ng} / \mathrm{ml}$ (normal range $0.8-2.0 \mathrm{ng} / \mathrm{ml}$ ), serum 
calcium $8.3 \mathrm{mg} / \mathrm{dl}$, potassium $4.6 \mathrm{mmol} / \mathrm{L}$, sodium $137 \mathrm{mmol} / \mathrm{L}$, magnesium $3.13 \mathrm{mg} / \mathrm{dl}$, and a normal hemogram, liver and renal function tests. She had persistent vomiting and also developed diplopia, blurring and yellowing of vision within two hours of admission along with intermittent episodes of bradycardia along with hypotension (systolic BP up to $70 \mathrm{mmHg}$ ). Electrocardiographs initially showed variable and prolonged PR [Figure 1] with atrial ectopics, which subsequently converted into complete heart block. Prophylactically transcutaneous pacing was applied to gain time for temporary pacemaker insertion as the patient continued to have episodes of symptomatic bradycardia (heart rate going down up to 30 /minute). Immediate cardiology opinion was taken and temporary pacemaker was inserted [Figure 2]. In view of high serum digoxin levels, presence of bradyarrhythmias with hypotension and nonavailability of Fab fragments, hemoperfusion with resin-based cartridge (HA280 resin hemoperfusion cartridge, Jafron Biomedical Co. Ltd., China) was done over 4 hours after taking nephrology opinion and written informed consent from the attendants. Lack of adequate literature about safety and efficacy of the procedure were carefully explained to the attendants. Patient was closely observed and platelets, coagulation profile, serum electrolytes and digoxin levels [Table 1] were monitored regularly. Patient tolerated the procedure well and there were no associated side effects, fall in platelet levels or procedure-related complications.

Patient showed gradual symptomatic improvement with clearing of vision and resolution of nausea and vomiting within 4 hours of resin hemoperfusion. Her heart rate also improved and her atrioventricular block also got corrected over the next 24 hours. Serum digoxin levels dropped to $3.06 \mathrm{ng} / \mathrm{ml}$ after 24 hours and to $2.56 \mathrm{ng} / \mathrm{ml}$ after 36 hours of resin hemoperfusion. Temporary pacemaker was kept in situ, on demand mode, for 24 hours after complete resolution of symptoms and serum digoxin levels coming in nontoxic range. She continued to remain asymptomatic and was discharged after 4 days of hospitalization.

\section{Discussion}

Digoxin is widely used but has a narrow therapeutic index. Serum digoxin levels below $0.8 \mathrm{ng} / \mathrm{ml}$ are considered subtherapeutic whereas, levels more than $2.0 \mathrm{ng} / \mathrm{ml}$ may be toxic. Toxic manifestations include cardiac and non-cardiac manifestations. Patient may either develop brady or tachy-arrhythmias. Electrocardiographic changes may include premature ventricular contractions, atrial fibrillation or flutter, nonparoxysmal atrioventricular junctional tachycardia or atrioventricular blocks. But none

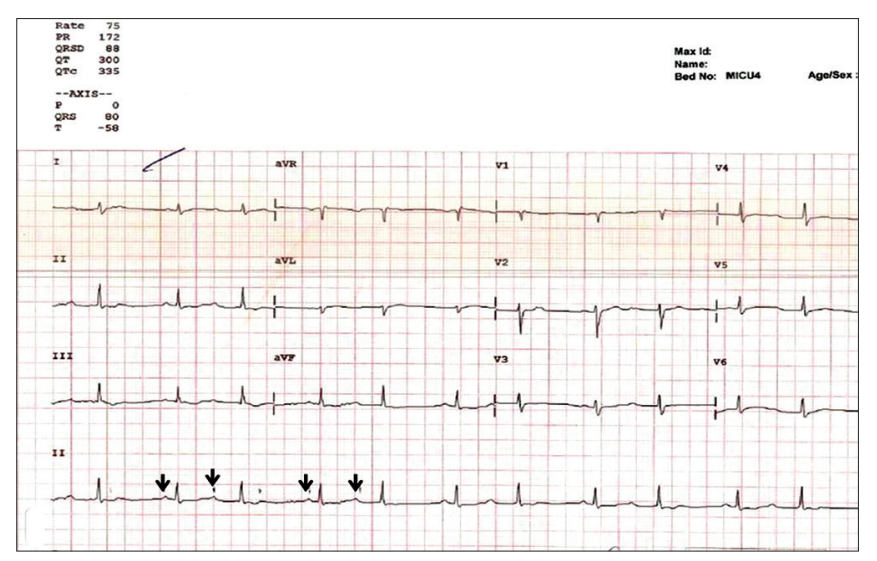

Figure I: Electrocardiograph showing prolonged and varying PR interval (arrows)

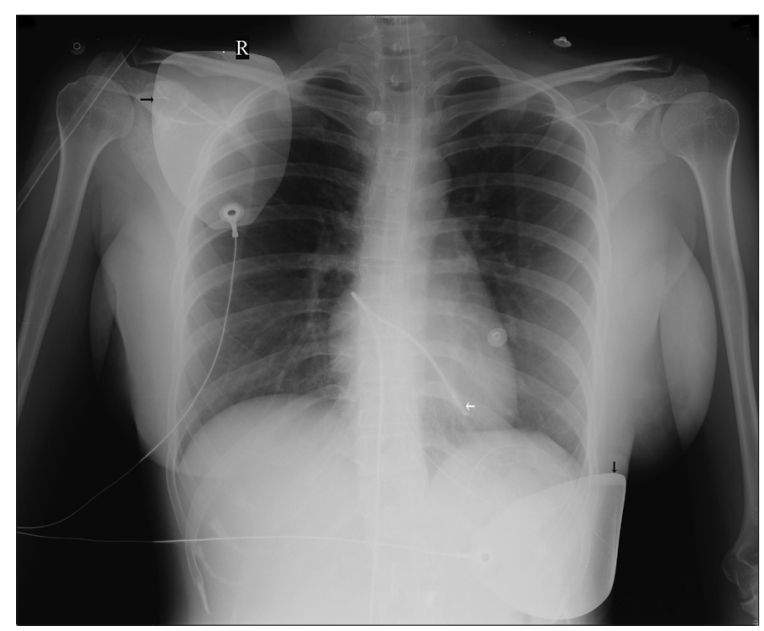

Figure 2: Chest $\mathrm{X}$-ray showing external pacing pads (black arrows) and temporary internal pacemaker (white arrow)

Table I: Serum digoxin levels during resin hemoperfusion

\begin{tabular}{lccccc}
\hline Time & $30 \mathrm{~min}$ & $60 \mathrm{~min}$ & $120 \mathrm{~min}$ & $180 \mathrm{~min}$ & $240 \mathrm{~min}$ \\
\hline Prefilter & $5.41 \mathrm{ng} / \mathrm{ml}$ & $5.37 \mathrm{ng} / \mathrm{ml}$ & $5.23 \mathrm{ng} / \mathrm{ml}$ & $4.50 \mathrm{ng} / \mathrm{ml}$ & $4.12 \mathrm{ng} / \mathrm{ml}$ \\
Postfilter & $1.39 \mathrm{ng} / \mathrm{ml}$ & $2.32 \mathrm{ng} / \mathrm{ml}$ & $2.46 \mathrm{ng} / \mathrm{ml}$ & $2.20 \mathrm{ng} / \mathrm{ml}$ & $2.12 \mathrm{ng} / \mathrm{ml}$ \\
\hline
\end{tabular}

of these are pathognomonic of digoxin toxicity. Noncardiac symptoms may include nausea, vomiting, lethargy, anorexia, headache or confusion. Rarely, patients may develop visual disturbances including diplopia, blurred or yellow vision, as in the present case. Coexistent electrolyte imbalance, especially hypercalcemia, hypokalemia and hypomagnesemia can potentiate digoxin toxicity.

If the patient presents within 4 hours of drug ingestion, immediate gastric lavage may be done. Activated charcoal (100 gm) may be given per oral even if the patients presents outside the 4 hours window, to improve gastrointestinal clearance. ${ }^{[4]}$ Immediate management of cardiac manifestations primarily includes management of heart block with repeated doses of atropine. Resistant 
cases may also require temporary pacing. Malignant ventricular dysrhythmias can be managed with betablockers, lignocaine or phenytoin.

Specific therapy of digoxin toxicity aimed at rapidly reducing serum digoxin concentration involves transfusion of Fab fragments. ${ }^{[2,3]}$ But the criteria for using digoxin specific antibody fragments are unclear and serum digoxin level alone may not be a good indicator. ${ }^{[5]}$ However, patients with lifethreatening arrhythmias like multifocal ectopic beats, atrioventricular conduction disorders (grade 2 and 3 block), ventricular tachycardias and relapsing ventricular fibrillation should be considered for therapy with Fab fragments. ${ }^{[6]}$

As Fab fragments are not widely available alternative measures to rapidly reduce digoxin concentration have been tried. ${ }^{[7-10]}$ Digoxin has a molecular weight of $780.95 \mathrm{~g} /$ $\mathrm{mol}$ and is insoluble in water. Peak serum concentrations of digoxin, after oral ingestion, occur at 30 to 90 minutes. Only $25 \%$ of digoxin plasma is bound to protein and it is mainly excreted through kidneys and has a serum halflife of 36-48 hours in adults with normal renal function. Hemodialysis is not effective in digoxin overdose due to its large volume of distribution. ${ }^{[7]}$ However, digoxin can be effectively removed by hemoperfusion with charcoal or resin filters. ${ }^{[8-10]}$ Resin hemoperfusion has been shown to be useful in managing patients with various intoxications including tricyclic antidepressant, chloral hydrate, and mushroom poisoning. ${ }^{[11]}$ Even though there are reservations regarding its use in digoxin overdose, ${ }^{[7]}$ resin hemoperfusion may be tried for drugs like digoxin, which have a high lipid solubility and it has been used successfully in a few cases. ${ }^{[9-11]}$
Hence, resin hemofilteration may be successfully and safely used as an alternative therapy, in conjunction with other supportive measures, to manage patients with digoxin toxicity especially when Fab fragments are unavailable.

\section{References}

1. Sanaei-Zadeh H, Valian Z, Zamani N, Farajidana H, Mostafazadeh B Clinical features and successful management of suicidal digoxin toxicity without use of digoxin-specific antibody (Fab) fragments--is it possible? Trop Doct 2011;41:108-10.

2. Antman EM, Wenger TL, Butler VP Jr, Haber E, Smith TW. Treatment of 150 cases of life-threatening digitalis intoxication with digoxinspecific Fab antibody fragments. Final report of a multicenter study. Circulation 1990;81:1744-52.

3. Wenger TL, Butler VP Jr, Haber E, Smith TW. Treatment of 63 severely digitalis-toxic patients with digoxin-specific antibody fragments. J Am Coll Cardiol 1985;5:118A-23A.

4. Levy G. Gastrointestinal clearance of drugs with activated charcoal. N Engl J Med 1982;307:676-8.

5. Springer M, Olson KR, Feaster W. Acute massive digoxin overdose: Survival without use of digitalis-specific antibodies. Am J Emerg Med 1986;4:364-8.

6. Smolarz A, Roesch E, Lenz E, Neubert H, Abshagen P. Digoxin specific antibody (Fab) fragments in 34 cases of severe digitalis intoxication. J Toxicol Clin Toxicol 1985;23:327-40

7. Warren SE, Fanestil DD. Digoxin overdose: Limitations of hemoperfusion and hemodialysis. JAMA 1979;242:2100-1.

8. Critchley JA, Critchley LA. Digoxin toxicity in chronic renal failure: Treatment by multiple dose activated charcoal intestinal dialysis. Hum Exp Toxicol 1997;16:733-5.

9. Smiley JW, March NM, Del Guercio ET. Hemoperfusion in the management of digoxin toxicity. JAMA 1978;240:2736-7.

10. Mathieu D, Gosselin B, Nolf M, Dupuis B, Marchandise X, Boidein M, et al. Massive digitoxin intoxication. Treatment by amberlite XAD 4 resin hemoperfusion. J Toxicol Clin Toxicol 1982;19:931-50.

11. Heath A, Delin K, Edén E, Mårtensson E, Selander D, Wickström I, et al. Hemoperfusion with Amberlite resin in the treatment of selfpoisoning. Acta Med Scand 1980;207:455-60.

How to cite this article: Juneja D, Singh O, Bhasin A, Gupta M, Saxena S, Chaturvedi A. Severe suicidal digoxin toxicity managed with resin hemoperfusion: A case report. Indian J Crit Care Med 2012;16:231-2.

Source of Support: Nil, Conflict of Interest: None declared. 